\title{
LEVANDO GARY KING A SÉRIO: DESENHOS DE PESQUISA EM CIÊNCIA POLÍTICA'
}

\author{
Dalson Britto Figueiredo Filho ${ }^{2}$ \\ Ranulfo Paranhos 3 \\ Enivaldo Carvalho da Rocha 4 \\ José Alexandre da Silva Jr5 \\ Manoel Leonardo Wanderley Duarte Santos ${ }^{6}$
}

\begin{abstract}
Resumo:
Esse trabalho apresenta dez procedimentos que ajudam o pesquisador a melhorar a qualidade do seu desenho e/ou produto final de pesquisa. Em termos substantivos, nosso principal objetivo é iniciar um debate mais sistemático sobre a utilização de métodos e técnicas de pesquisa na Ciência Política brasileira. Nossas recomendações são as seguintes: (1) explicitar e justificar a questão de pesquisa; (2) descrever os métodos e as técnicas; (3) simplificar a hipótese de trabalho; (4) produzir inferências causais falsificáveis; (5) apresentar as limitações do desenho de pesquisa; (6) minimizar a complexidade da linguagem; (7) compartilhar a base de dados; (8) evitar gráficos nebulosos e tabelas poluídas e incompletas; (9) ser criticado antes de publicar e (10) escolher adequadamente os meios de divulgação.
\end{abstract}

Palavras-chave: desenho de pesquisa; replicabilidade; metodologia; Ciência Política.

\section{Resumen:}

Este artículo presenta diez pasos para ayudar a los investigadores a mejorar la calidad de su diseño y / o la búsqueda del producto final. En cuanto al fondo, nuestro principal objetivo es iniciar una discusión más sistemática de la aplicación de métodos y técnicas de investigación en la ciencia política brasileña. Nuestras recomendaciones son las siguientes: (1) explicar y justificar la pregunta de investigación; (2) describir los métodos y técnicas; (3) la simplificación de hipótesis; (4) producir inferencias causales falsables; (5) presenta limitaciones el diseño de la investigación; (6) reducir al mínimo la complejidad del lenguaje; (7) comparten la base de datos; (8) Evite los gráficos borrosos y mesas contaminadas e incompletas; y (9) siendo criticado antes de publicar, y (10) elegir medios adecuados de difusión.

Palabras-clave: diseño de investigación; replicabilidad, metodología, ciencia política.

\footnotetext{
${ }^{1}$ Agradecemos aos comentários de Humberto Mignozzetti, Camila Bastos e Natália Leitão a versão inicial desse artigo. $O$ trabalho também se beneficiou de sugestões recebidas durante o $8^{\circ}$ Encontro da Associação Brasileira de Ciência Política (ABCP) ocorrido em Gramado (RS) entre os dias 1 e 4 de agosto de 2012. Imprecisões remanescentes são inteiramente creditadas aos autores. Esse trabalho contou com aporte financeiro do CNPQ e da CAPES.

2 Doutorando em Ciência Política do Programa de Pós-Graduação em Ciência Política da Universidade Federal de Pernambuco. E-mail: dalsonbritto@yahoo.com.br

3 Professor de Ciência Política da Universidade Federal de Alagoas e Doutorando em Ciência Política do Programa de Pós-Graduação em Ciência Política da Universidade Federal de Pernambuco. E-mail: ranulfoparanhos@me.com

4 Professor do Dept $^{\circ}$ de Ciência Política da Universidade Federal de Pernambuco, Doutor em Estatística e Pós-Doutorando do Programa de Pós-Graduação em Ciência Política da Univ. Fed. de Minas Gerais. E-mail: enivaldocrocha@gmail.com

5 Professor de Ciência Política da Universidade Federal de Goiás e Doutorando em Ciência Política do Programa de Pós-Graduação em Ciência Política da Universidade Federal de Pernambuco.E-mai: jasjunior2007@yahoo.com.br

6 Professor do Dept $^{\mathrm{O}}$ de Ciência Política da Universidade Federal de Minas Gerais, Doutor em Ciência Política pela Universidade Federal de Pernambuco. E-mail: manoelsantos@fafich.ufmg.br
} 


\section{Abstract:}

This paper presents ten procedures that help scholars to improve research design and/or final paper quality. On substantive grounds, our main purpose is to start a more systematic debate regarding the use of methods and research techniques in the Brazilian political science. We recommend the following: (1) explicitly state and justify the research question; (2) precisely describe both methods and techniques; (3) state parsimonious hypothesis; (4) construct falsiable causal inferences; (5) clearly delineate research designs shortcomings; (6) minimize language complexity; (7) adopt data sharing as a standard procedure; (8) avoid both junk graphs and incomplete tables; (9) submit the work to academic scrutiny before publishing it and (10) carefully choose how to publicize the research results.

Keywords: research design; replication; methodology; Political Science.

This lack of focus on research design in social science statistics is as surprising as it is disappointing, since some of the most historically important works in the more general field of statistics are devoted to problems of research design.

King, Keohane e Verba

Any scientific investigation, be it the social or natural sciences, must begin with some structure or plan. This structure defines the number and type of entities or variables to be studied and their relationship to one another.

Paul Spector

\section{INTRODUÇÃO}

Em “Replication, Replication”, King (1995) argumenta que um componente essencial da atividade científica é a replicabilidade dos resultados de pesquisa. Em "How not to lie with statistics", King (2001) identifica uma série de erros recorrentes na pesquisa empírica em Ciência Política. Em "Publication, Publication”, King (2006) apresenta algumas regras sobre como produzir um artigo publicável7. Em comum, esses trabalhos oferecem diretrizes que contribuem para o avanço do conhecimento científico. Esse artigo segue nessa direção e apresenta dez procedimentos que ajudam a elevar a qualidade dos desenhos e/ou produtos final de pesquisa. Mas por que um artigo sobre metodologia?

O encontro da Associação Nacional de Pós-Graduação em Ciências Sociais (ANPOCS) de 2011 apresentou 38 Grupos de Trabalho. Em 2010 foram realizadas 37 Sessões Temáticas. O encontro da Associação Brasileira de Ciência Política (ABCP) de 2010 apresentou 26 mesas redondas e dez áreas temáticas. Nenhum deles discutiu

7 Gary King é professor na Universidade de Harvard e diretor do Institute for Quantitative Social Science. Para mais informações ver http://gking.harvard.edu/ 
métodos ou técnicas de pesquisa ${ }^{8}$. Para Marques (2007), "a discussão sobre método é relativamente rara entre nós, visto que não temos tradição de pensar em nossas explicações, nem tampouco nos modelos de análise que são mobilizados por nossa produção científica” (MARQUES, 2007, p. 141). Mais recentemente, em entrevista publicada no Boletim da Associação Brasileira de Ciência Política (ABCP) de fevereiro/março de 2012, o professor Fernando Limongi (USP) afirmou que "nossa formação metodológica é o calcanhar de Aquiles. Nossos alunos carecem de melhor formação nesta área. Os departamentos não têm formação forte em metodologia. É uma carência que precisamos suprir".

Para Soares (2005), existe uma hostilidade em relação aos métodos quantitativos e à Estatística (SOARES, 2005). Os trabalhos de Vianna et al (1988), Valle e Silva (1999) e Santos e Coutinho (2000) também sugerem que: a utilização de técnicas básicas de estatística descritiva ainda é bastante limitada nas Ciências Sociais no Brasil, independente do tipo de produção (artigos, dissertações ou teses). Similarmente, a utilização de técnicas qualitativas não tem melhor sorte. Para Soares (2005), a ausência de métodos quantitativos não significa a presença de métodos qualitativos. Regra geral, o padrão é o não método. Em particular, a escassez de cursos de métodos e técnicas, sejam eles quantitativos e qualitativos, acaba prejudicando a formação dos profissionais na área de Ciências Sociais, além de reduzir a qualidade técnica da produção acadêmica. Um dos principais esforços para minorar esse problema foi materializado através do curso de Metodologia Quantitativa (MQ) em Ciências Humanas realizado anualmente pelos departamentos de Sociologia e Ciência Política da Universidade Federal de Minas Gerais (UFMG). No plano internacional destaca-se a Escuela de Métodos de Análisis Sociopolítico (EMAS) organizado pela Universidade de Salamanca, o Summer Program in Quantitative Methods of Social Research (ICPSR), o Summer School in Methods and Techniques organizado pelo European Consortium for Political Research e a Essex Summer School in Social Sciences and Data Analysis. Entre 21 de janeiro a 08 de fevereiro de 2013 a International Political Science Association (IPSA) realizou um curso de verão na

8 O II Fórum de Pós-graduação em Ciência Política organizou uma Mesa Coordenada sobre metodologia. Foram inscritos apenas três trabalhos. Pereira Neto e Bernabel (2011) apresentaram uma introdução aos modelos hierárquicos Bayesianos. Oliveira (2011) apresentou uma análise dos artigos publicados nas revistas DADOS e RBCS e Figueiredo Filho et al (2011) apresentaram uma introdução ao p-valor. Em 2012, a ABCP incluiu não só um grupo de trabalho, mas também uma mesa redonda sobre metodologia. 
Universidade de São Paulo (USP) - Concepts, Methods, and Techniques in Political Science.

Acreditamos que a ausência de métodos quantitativos e qualitativos não é um evento independente de outros erros comuns tanto na formulação do desenho de pesquisa quanto na elaboração de trabalhos científicos em Ciência Política. Dessa forma, a principal contribuição desse trabalho é sistematizar condutas desejáveis sobre como produzir conhecimento científico.

Dentro dessa perspectiva, esse trabalho apresenta dez procedimentos que ajudam o pesquisador a melhorar a qualidade do seu desenho e/ou produto final de pesquisa. Em termos metodológicos, reproduzimos algumas das recomendações elaboradas pela literatura. Além disso, incluímos alguns dos componentes oriundos da experiência de ensino e pesquisa compartilhada pelos autores. Dividimos nossas recomendações em dois grupos: (a) substantivas e (b) procedimentais. As sugestões substantivas são as seguintes: (1) explicitar e justificar a questão de pesquisa; (2) descrever os métodos e as técnicas; (3) simplificar a hipótese de trabalho; (4) produzir inferências causais falsificáveis; e (5) apresentar as limitações do desenho de pesquisa. Por sua vez, sugerimos as seguintes recomendações procedimentais: (6) minimizar a complexidade da linguagem; (7) compartilhar a base de dados; (8) evitar gráficos nebulosos e tabelas poluídas e incompletas; (9) ser criticado antes de publicar e (10) escolher adequadamente os meios de divulgação.

Para executar o referido desenho de pesquisa, o artigo está subdividido em dez seções. Em cada uma enfatizamos um procedimento diferente que ajuda a melhorar a qualidade dos desenhos e/ou produto final de pesquisa.

\section{EXPLICITAR E JUSTIFICAR A QUESTÃO DE PESQUISA9}

A primeira regra para agregar qualidade a um artigo/desenho de pesquisa é explicitar a questão de pesquisa. Por um motivo muito simples: quanto mais nebulosa for a pergunta, menor é a chance do leitor se interessar em ler o trabalho. De forma mais séria, quando a questão de pesquisa é nebulosa, fica difícil, inclusive, de avaliar em que medida os resultados observados respondem satisfatoriamente a indagação proposta pelo trabalho. Para Schmitter (2002), o pesquisador deve chamar a atenção do seu leitor/avaliador logo no início e de forma irresistível, com um problema de pesquisa. Isso é importante porque, uma vez que ele perca o interesse no que você se propõe a fazer, será muito difícil que volte atrás (SCHMITTER, 2002, p. 01). Para King, Keohane e Verba (1994),

\footnotetext{
9 A ênfase em explicitar claramente a questão de pesquisa é um dos pontos enfatizados no
} Ronald Coase Workshop in Institutional Analysis. Ver: http://www.coase.org/ 
all research projects in the social sciences should satisfy two criteria. First, a research project should pose a question that is important in the real world (...) Second, a research project should make a specific contribution to an identifiable scholarly literature by increasing our collective ability to construct verified scientific explanations of some aspect of the world (KING, KEOHANE e VERBA, 1994, p. 15).

O pesquisador deve ter em mente que o tempo do leitor é um recurso escasso. Portanto, a questão de pesquisa não deve ser inferida nem deduzida, mas sim claramente explicitada. Para Spector (1981),

any investigation requires several steps to complete. First, the investigator must formulate a researchable question. This question may be in the form of a hypothesis that certain relationship exist among variables, or it may be of an exploratory nature, essentially asking what is the relationship among variables. A research question may begin in a loosely formulated form, but must eventually be stated such that a testable hypothesis or model is generated. The more precise the question, the easier it will be to answer (SPECTOR, 1981, p. 19).

Por exemplo, Amorim Neto e Santos (2006) indagam de início: "que fatores induzem o comportamento dos legisladores nos sistemas presidencialistas latinoamericanos?” (AMORIM NETO e SANTOS, 2003, p. 661). Ou seja, já no começo o leitor identifica qual é a questão de pesquisa, sendo mais fácil avaliar em que medida o trabalho cumpriu satisfatoriamente os seus objetivos. Tão importante quanto explicitar a questão de pesquisa é apresentar a justificativa do trabalho. Para Schmitter (2002),

desenvolva uma relação entre o seu tópico/tema com a literatura existente, explicando o que se sabe sobre ele, e como o seu trabalho pode vir a acrescentar algo a este campo, ou mesmo diferir do que nele já foi feito (...) Complete sua avaliação crítica sobre o que foi escrito (e o que não foi) acerca do tema. Uma declaração de qual é a sua postura em relação a essa produção, juntamente com a visão que você pretende lançar sobre o problema, também é fundamental (SCHMITTER, 2002, p. 01).

A justificativa do trabalho deve responder a seguinte questão: por que, sequer, deveríamos nos importar com a sua pesquisa? O pesquisador deve deixar claro qual é a importância da questão de pesquisa para o desenvolvimento do conhecimento em uma determinada área de investigação. No que diz respeito ao tamanho, o pesquisador deve exercitar sua capacidade de síntese. Se você não consegue escrever sua introdução e justificativa de forma objetiva, não culpe a complexidade do objeto, nem mesmo argumente que é preciso mais páginas para explicar o problema. $\mathrm{O}$ que pode ser dito em dez páginas, fica melhor se for dito em cinco. 
Outra vantagem de escrever de forma sintética é respeitar os limites mínimos e máximos de caracteres que são adotados pela maior parte dos periódicos especializados. O mesmo pode ser dito em relação ao tamanho dos resumos submetidos a congressos. Dessa forma, quanto antes o pesquisador se acostumar a escrever dentro de limites específicos, tanto mais eficiente será a sua atividade de pesquisa. Nossa primeira recomendação é apresentar claramente a questão de pesquisa e a justificativa do trabalho.

\section{DESCREVER OS MÉTODOS E AS TÉCNICAS}

King, Keohane e Verba (1994) afirmam que "the most important rule for all data collection is to report how the data were created and how we came to possess them" (KING, KEOHANE e VERBA, 1994, p. 51). O leitor não deve ser tratado como detetive ou clarividente. Pelo contrário, deve-se deixar claro todos os procedimentos metodológicos. Para King, Keohane e Verba (1994), "scholars should always record the exact methods, rules, and procedures used to gather information and draw inferences so that another researcher can do the same thing and draw the same conclusion" (KING, KEOHANE e VERBA, 1994, p. 27). Uma pesquisa que não descreve exatamente como os dados foram coletados torna-se irreplicável e, consequentemente, não falsificável ${ }^{10}$.

Além de apresentar os métodos e técnicas, é importante também descrever as variáveis utilizadas. Deve-se começar pelo nível de mensuração, apresentando a estatística descritiva. Outro procedimento desejável é estabelecer uma discussão conceitual sobre a operacionalização das variáveis, contemplando a validade e a confiabilidade dos indicadores. Sempre que possível, deve-se disponibilizar o endereço eletrônico no qual os dados podem ser acessados. Também é importante reportar os softwares utilizados e transcrever os códigos (sintax).

Em síntese, o pesquisador deve maximizar as chances de replicabilidade do seu estudo. Para King, Keohane e Verba (1994), “all data and analyses should, insofar as possible, be replicable. Replicability applies not only to the data, so that we can see whether our measures are reliable, but to the entire reasoning process used in producing conclusions" (KING, KEOHANE e VERBA 1994, p. 26). Nossa segunda recomendação é a descrever detalhadamente os métodos e das técnicas.

\footnotetext{
10 Para Popper (1968) não importa se nossas hipóteses de pesquisa foram extraídas da teoria, da observação empírica, ou se simplesmente tropeçamos nelas: em termos metodológicos, o que realmente importa é se elas são falsificáveis. O falsificacionismo consiste em tentar repetidas vezes demonstrar, a partir da realidade, que uma determinada teoria é falsa. Quanto mais a teoria resistir à tentativa de ser falseada, tanto melhor será a teoria.
} 


\section{SIMPLIFICAR A HIPÓTESE DE TRABALHO}

Muitos trabalhos não apresentam a hipótese de pesquisa de forma clara e/ou apresentam algo como se fosse hipótese, mas que na verdade se trata de algo indefinido. Hipóteses mal formuladas limitam a credibilidade dos resultados de pesquisa, comprometendo o desenvolvimento do conhecimento científico.

O primeiro passo para simplificar uma hipótese de trabalho é entender primeiramente o que é uma hipótese. Van Evera (1997) define hipótese como

uma conjectura da relação esperada entre dois fenômenos. Assim como leis, hipóteses podem ser de dois tipos: causais (A causa B) e não causais - A e B são causados por C; dessa forma A e B são correlacionados, mas nem A causa B nem B causa A (VAN EVERA, 1997, p. 09).

Para Collier, Mahoney e Seawright (2004), uma hipótese é uma conjectura a respeito de uma relação entre uma ou mais variáveis independentes e uma variável dependente (COLLIER, MAHONEY e SEAWRIGHT, 2004). Definimos hipótese como uma conjectura a respeito da relação entre uma variável independente (VI) e uma variável dependente (VD). Uma hipótese clara tem três componentes básicos: (1) uma relação esperada; (2) uma variável independente e (3) uma variável dependente. O Quadro 1 ilustra os estágios que devem ser seguidos para transformar uma hipótese geral em uma hipótese específica.

Quadro 1- Simplificando a hipótese de trabalho

\begin{tabular}{|c|c|}
\hline Exemplo & Estágio \\
\hline $\begin{array}{c}\text { Existe uma relação entre } \\
\text { desenvolvimento econômico e } \\
\text { democratização }\end{array}$ & $\begin{array}{l}\text { O pesquisador identificou as variáveis (desenvolvimento } \\
\text { econômico e nível de democratização), afirmando que existe } \\
\text { uma relação entre elas. Dizer que X e Y estão relacionadas é } \\
\text { necessário, mas não é suficiente. A hipótese é muito geral e } \\
\text { pouco informativa. }\end{array}$ \\
\hline $\begin{array}{l}\text { Existe uma correlação entre } \\
\text { desenvolvimento econômico e } \\
\text { democratização }\end{array}$ & $\begin{array}{l}\text { Ao utilizar o termo correlação, o pesquisador tornou a } \\
\text { hipótese ligeiramente mais específica na medida em que } \\
\text { antecipou o tipo de relação esperada. Esse procedimento é } \\
\text { necessário, mas também não é suficiente. }\end{array}$ \\
\hline $\begin{array}{c}\text { Existe uma correlação positiva entre } \\
\text { desenvolvimento econômico e } \\
\text { democratização }\end{array}$ & $\begin{array}{l}\text { O pesquisador agora definiu o tipo de relação (correlação) } \\
\text { e a direção esperada (positiva). No entanto, um objetivo } \\
\text { central da pesquisa científica é fazer inferências causais } \\
\text { falsificáveis. Logo, deve-se indicar a direção da causalidade } \\
\text { esperada entre as variáveis. Na ausência de teoria sobre o } \\
\text { assunto, essa formulação é adequada. }\end{array}$ \\
\hline $\begin{array}{l}\text { O desenvolvimento econômico exerce um } \\
\text { efeito positivo sobre o nível de } \\
\text { democratização }\end{array}$ & $\begin{array}{l}\text { O pesquisador identificou uma variável independente } \\
\text { (desenvolvimento econômico), uma variável dependente } \\
\text { (nível de democratização) e uma relação esperada entre } \\
\text { elas (positiva). Ou seja, o pesquisador estabeleceu a direção } \\
\text { da causalidade (desenvolvimento econômico aumenta } \\
\text { democracia). Essa é a formatação de hipótese mais } \\
\text { adequada. }\end{array}$ \\
\hline
\end{tabular}

Fonte: elaboração dos autores. 
O próximo passo para simplificar a hipótese de trabalho é a parcimônia. $\mathrm{O}$ pesquisador deve ser parcimonioso não só em termos substantivos, mas também do ponto de vista técnico. A parcimônia substantiva diz respeito ao número de variáveis e relações esperadas que são incluídas em uma mesma hipótese. Por exemplo: “a taxa de homicídios deve estar positivamente associada ao índice de Desenvolvimento Humano (IDH), negativamente correlacionada com o número de policiais per capita, positivamente associada ao nível de desemprego e estatisticamente independente da quantidade de condenações”. O referido enunciado pode ser considerado uma hipótese de acordo com a definição proposta por Collier, Mahoney e Seawright (2004). No entanto, essa hipótese apresenta uma variável dependente (taxa de homicídios), quatro variáveis independentes (IDH, número de policiais per capita, desemprego e número de condenações) e quatro relações esperadas $(+,-,+, 0)$. De acordo com o nosso modelo, essa formulação viola o pressuposto da parcimônia. Do ponto de vista do leitor, quanto mais relações são incluídas em uma mesma hipótese, mais complicado para entender os propósitos do trabalho.

Para garantir uma hipótese parcimoniosa é necessário que o próprio artigo/desenho de pesquisa tenha um foco específico. Para Weingast (1995),

a good test of whether you're sufficiently focused on one main point is to see whether you can summarize the paper's main argument in one paragraph. If you fail, you are probably not ready to write a cogent paper. If you succeed, you are not only ready to write the paper, but you've finished a first draft of your abstract (WEINGAST, 1995, p. 02).

A parcimônia técnica refere-se à operacionalização. A hipótese deve ser escrita na voz ativa e não deve ultrapassar três linhas. $O$ quadro abaixo apresenta a mesma hipótese escrita de formas diferentes.

Quadro 2 - Diferentes hipóteses, mesma ideia

\begin{tabular}{|l|l|}
\hline \multicolumn{1}{|c|}{ Hipótese não parcimoniosa } & Hipótese parcimoniosa \\
\hline Em um mundo cada vez mais globalizado e & \\
interdependente, a estabilidade política dos & \\
países é influenciada negativamente pelo tipo & Regimes presidencialistas exercem um efeito \\
de regime adotado em que regimes & negativo sobre a estabilidade política \\
presidencialistas são mais instáveis do que & \\
regimes parlamentaristas. & \\
\hline
\end{tabular}

Fonte: elaboração dos autores.

A hipótese não parcimoniosa apresenta elementos desnecessários. Não existe ganho analítico na frase - em um mundo cada vez mais globalizado e interdependente. Além disso, a voz passiva dificulta a compreensão do fenômeno de interesse. Na 
hipótese parcimoniosa é mais fácil identificar a relação esperada entre as variáveis, pois fica evidente a direção da causalidade.

Considere a seguinte afirmação: os deputados votam de acordo com a indicação dos líderes partidários, pois almejam receber benefícios oriundos das prerrogativas dos líderes ao mesmo tempo em que temem sofrer represálias. A variável dependente é o voto do deputado. A variável independente é a indicação do líder. O restante - pois almejam receber benefícios oriundos das prerrogativas dos líderes ao mesmo tempo em que temem sofrer represálias - é a explicação do fenômeno ou o mecanismo causal ${ }^{11}$. No entanto, o leitor pode ser levado a acreditar que benefícios e represálias são as variáveis independentes. O pesquisador não deve misturar hipótese e explicação em uma mesma oração. Dizer "fumar causa câncer" (hipótese) é diferente de descrever os mecanismos causais que explicam a relação entre a quantidade de nicotina e o surgimento de tumores (explicação ou mecanismo causal). Da mesma forma, não se deve misturar a hipótese e a justificativa na mesma frase. Após revisar diferentes periódicos em Ciências Sociais, além da experiência docente compartilhada, identificamos alguns erros típicos na formulação das hipóteses de trabalho.

- Hipótese sem variável independente (VI): Recife é uma cidade violenta

Ainda que a violência possa ser estimada de diferentes formas (taxa de homicídios por 100 mil, número de furtos, etc.), o pesquisador não identificou nenhuma variável independente. O que explica a violência? Não existe nenhuma informação no enunciado acima que auxilie o leitor a entender que fatores explicam a variável dependente.

- Hipótese sem variável dependente (VD): As variáveis socioeconômicas são importantes para explicar diferentes aspectos da realidade social.

A afirmação acima tem um problema fundacional: ausência de uma variável dependente bem definida. Diferentes aspectos da realidade social é uma categoria excessivamente geral e que pode ser operacionalizada de formas distintas. Uma

\footnotetext{
${ }^{11}$ A formatação mais adequada dessa hipótese seria a seguinte: existe uma correlação positiva entre o voto do líder e o voto do deputado (na ausência de teoria sobre o assunto) ou o voto do líder exerce um efeito positivo sobre o voto do deputado (utilizando a teoria disponível sobre o assunto, no caso, Figueiredo e Limongi, 1999).
} 
hipótese sem variável dependente é um indicativo de que o pesquisador não definiu acuradamente qual é o seu problema de pesquisa.

- Hipótese sem variável (VI e VD): Os determinantes econômicos são dominantes para compreender os diferentes aspectos da realidade social.

Metodologicamente, não faz sentido falar que uma variável é dominante já que o pesquisador deveria identificar as variáveis que são dominadas. Se o pesquisador considera que os determinantes econômicos são mais importantes do que outras variáveis, ele deve formular a sentença exprimindo esse sentimento (ex. entre as diferentes variáveis explicativas - cultura, gênero, idade, etc. - os determinantes econômicos são as variáveis mais importantes para compreender diferentes aspectos da realidade social).

Segundo, não é possível testar uma hipótese que se propõe a compreender fenômenos. Hipóteses devem estabelecer relações entre variáveis e/ou diferenças entre grupos. A interpretação/compreensão é um processo exógeno e complementar à formulação e teste de hipóteses. Ao testar a hipótese de que, em condições normais de temperatura e pressão (CNTP), a água entra em ebulição a $100{ }^{\circ} \mathrm{C}$, nada pode ser dito em relação aos mecanismos causais que explicam esse fenômeno. A compreensão/interpretação é um processo posterior ao teste de hipótese em que o pesquisador interpreta substantivamente os resultados de pesquisa, identificando o mecanismo causal responsável pelos resultados observados.

- Hipótese indeterminada: O aumento e a redução da violência estão relacionados com fatores socioeconômicos.

Quando uma variável independente (fatores socioeconômicos), ao mesmo tempo, exerce um efeito positivo e um impacto negativo sobre uma determinada variável dependente, tem-se uma hipótese indeterminada. Afinal, fatores socioeconômicos aumentam ou diminuem a violência? O pesquisador deve evitar a elaboração de hipóteses indeterminadas já que elas são, por definição, não testáveis.

- Hipótese sem uma direção esperada entre VI e VD: Existe uma relação entre desigualdade social e violência.

Dificilmente o pesquisador vai encontrar variáveis ortogonais, ou seja, que são absolutamente independentes. Ao afirmar que existe relação entre X e Y, o pesquisador minimiza as chances de estar errado. Isso porque uma relação de qualquer magnitude (fraca, média ou forte) e em qualquer direção (positiva ou negativa) corrobora seu argumento. Quão informativo é um desenho de pesquisa/artigo que se propõe a 
responder uma questão de pesquisa dessa natureza? O pesquisador deve sempre estabelecer a direção teoricamente esperada entre as variáveis independente e dependente. Na ausência de teoria disponível sobre o assunto, o pesquisador tem mais liberdade para adotar uma perspectiva exploratória.

Nossa terceira recomendação é simplificar a hipótese de trabalho.

\section{PRODUZIR INFERÊNCIAS CAUSAIS FALSIFICÁVEIS}

Partindo do pressuposto de que o principal objetivo da ciência é explicar a realidade, sempre que houver teoria disponível, o desenho de pesquisa deve ser formatado no sentido produzir inferências causais falsificáveis. Inferência no sentido de utilizar fatos/informações disponíveis para concluir a respeito de fatos/informações indisponíveis (KING, KEOHANE e VERBA, 1994). Causais no sentido de estabelecer uma relação de causa e efeito entre variáveis de tal sorte que a ocorrência de $x$ aumente ou reduza a probabilidade de ocorrência de $y$ (GERRING, 2001; 2005). E falsificáveis no sentido de que a qualquer momento a inferência causal pode ser demonstrada falsa por outro desenho de pesquisa concorrente (POPPER, 1944). Em suma, a hipótese de trabalho deve estabelecer uma relação causal falsificável entre uma ou mais variáveis independentes e uma variável dependente. Mas o que é relação causal afinal?

Causalidade é um dos conceitos mais controversos da Filosofia e da Ciência. Para Chen e Popovic (2002), especialistas de várias disciplinas não chegaram (e provavelmente nunca chegarão) a um consenso a respeito da definição de causalidade (CHEN e POPOVIC, 2002). Para King, Keohane e Verba (1994),

the causal effect is the difference between the systematic component of observations made when the explanatory variables takes one value and the systematic component of comparable observations when the explanatory variable takes on another value (KING, KEOHANE e VERBA, 1994, p. 81) ${ }^{12}$.

A definição proposta por King, Keohane e Verba (1994) pode ser consideradas como uma variação do conceito de causalidade estabelecido por Rubin (1974):

let $y(E)$ be the value of $Y$ measured at $t_{2}$ on the unit, given the unit received the experimental treatment $\mathrm{E}$ initiated at $\mathrm{t}_{1}$; let $\mathrm{y}(\mathrm{C})$ be the value of $\mathrm{Y}$ measured at $t_{2}$ on the unit given that the unit received the control treatment $C$ initiated at $t_{1}$; then $y(E)-y(C)$ is the causal effect

${ }_{12} \mathrm{Em}$ outro momento os autores afirmam que "causal inference thus becomes a process whereby each conclusion becomes the occasion for further research to refine and test it. Through successive approximations we try to come closer and closer to accurate causal inference" (KING, KEOHANE e VERBA, 1994, p. 33). 
of the $\mathrm{E}$ versus $\mathrm{C}$ treatment on $\mathrm{Y}$ for that trial, that is, for that particular unit and the times $\mathrm{t}_{1}, \mathrm{t}_{2}$ (RUBIN, 1974, p. 689).

Definimos causalidade como a diferença entre os valores assumidos pela variável dependente a partir da variação da variável independente, de modo que a ocorrência de $x$ influencia a probabilidade da ocorrência de $y$.

O próximo passo é determinar os critérios que o pesquisador pode utilizar para identificar uma relação causal. Pearl (2000) identifica três pressupostos: (1) associação entre as variáveis (correlação); (2) precedência temporal e (3) não-espuriosidade da relação. A Figura 1 ilustra esses pressupostos.

Figura 1 - Pressupostos da causalidade

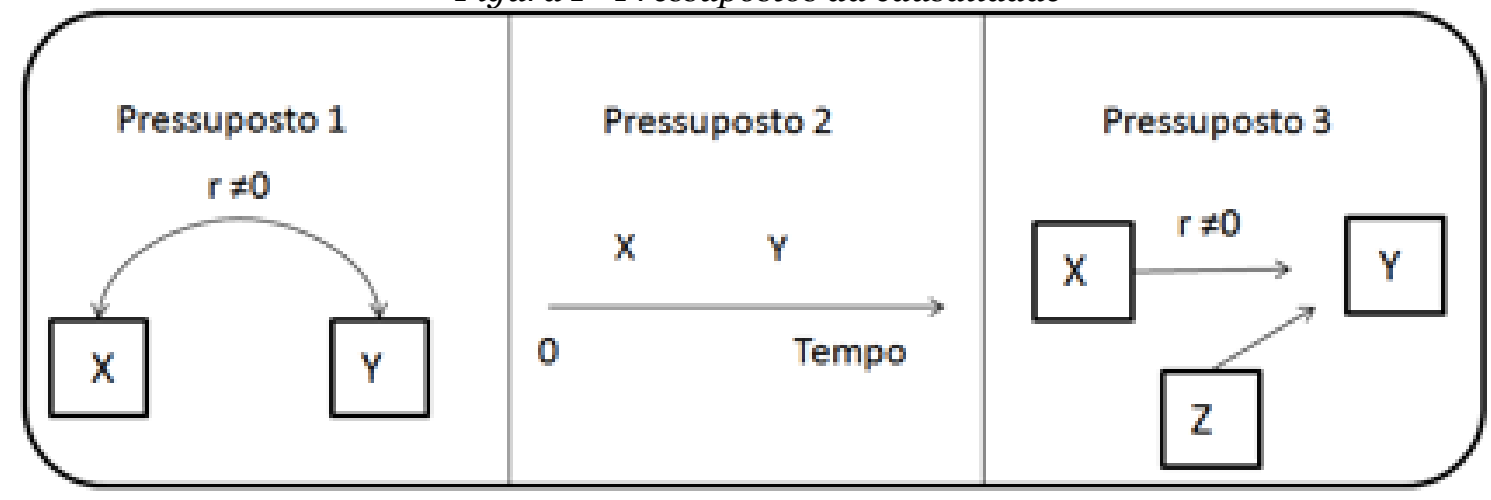

Fonte: Pearl (2000).

O primeiro pressuposto, correlação entre as variáveis, sugere que a ocorrência de $y$ não é independente da ocorrência de $x$. Duas variáveis são independentes quando a distribuição condicional de $y$ não varia de acordo com a distribuição de $x$. Em termos técnicos, considera-se que $x$ e $y$ são estatisticamente independentes quando não existe associação entre a distribuição de suas respectivas frequências ou variâncias. Logo, o primeiro pressuposto para identificar a presença de uma relação causal é a existência de correlação entre $x$ e $y(r \neq 0)$.

O segundo pressuposto, precedência temporal, é intuitivo já que o que aconteceu depois não pode causar o que aconteceu antes. Para considerar $x$ como causa de $y$ é necessário que $x$ ocorra antes de $y$. Por exemplo, um indivíduo é alvejado $(x)$ e depois vem a falecer $(y)$. Infere-se que a morte do indivíduo (y) é explicada pelo evento anterior $(x)$, sendo impossível observar a ocorrência de $y$ antes da ocorrência de $x$. Dessa forma, a segunda condição para identificar uma relação causal é a assimetria temporal entre $x$ e $y$.

O terceiro pressuposto, não-espuriosidade da relação, exige que para se considerar $x$ como causa de $y$ deve-se eliminar causas concorrentes, $z$. Nas palavras de Kenny (2004), "for an relationship between $X$ and $Y$ to be nonspurious, there must not 
be a $Z$ that causes both $X$ and $Y$ such that the relationship between $X$ and $Y$ vanishes once $Z$ is controlled" (KENNY, 2004, p. 3/4). Suponha que um indivíduo é alvejado (x), mas também é envenenado (z) e depois vem a óbito. Para que $x$ possa ser considerado causa é necessário que o seu efeito seja observado, independente da presença de $z$. Gerring (2001) sugere critérios bastante semelhantes, mas adiciona um elemento. $\mathrm{O}$ quadro abaixo sumariza essas informações.

Quadro 3 - Relação causal (critérios adicionais)

\begin{tabular}{|c|c|}
\hline Critério & Definição \\
\hline Diferenciação (exogeneidade) & $\begin{array}{l}\text { Para que } x \text { possa ser considerado causa de } y \text {, é } \\
\text { necessário diferenciar } x \text { de } y \text {. Ou seja, a causa deve } \\
\text { se diferenciar lógica e empiricamente da } \\
\text { consequência a ser explicada. }\end{array}$ \\
\hline Antecedência temporal (priority) & $\begin{array}{l}\text { Para que } x \text { possa ser considerado causa de } y \text {, a } \\
\text { ocorrência temporal de } x \text { deve preceder a } \\
\text { ocorrência temporal de } y(x \text { deve ocorrer antes de } \\
y) \text {. }\end{array}$ \\
\hline $\begin{array}{l}\text { Independência (exogeneidade, } \\
\text { assimetria, recursividade) }\end{array}$ & $\begin{array}{l}\text { Para que } x \text { possa ser considerado causa de } y \text {, a } \\
\text { ocorrência de } x \text { deve ser independente da } \\
\text { ocorrência de } y \text { (y não pode influenciar a } \\
\text { probabilidade da ocorrência de } x \text { ). }\end{array}$ \\
\hline Contingência & $\begin{array}{l}\text { Para que } x \text { possa ser considerado causa de } y, x \text { não } \\
\text { pode ser contingente de } z \text { (deve-se excluir causas } \\
\text { concorrentes). }\end{array}$ \\
\hline
\end{tabular}

Fonte: elaboração dos autores.

O critério de diferenciação entre $x$ e $y$ parece ser evidente, ou seja, para que $x$ possa ser considerado causa de $y$ deve existir uma distinção lógica e empírica entre ambos. O segundo critério elencado por Gerring (2001) equivale ao pressuposto 2 identificado por Pearl (2000): $x$ deve ocorrer antes de $y$. O terceiro pressuposto diz respeito à independência de $x$ em relação a $y$. A ocorrência de $y$ não pode influenciar a ocorrência de $x$.

O quarto critério diz respeito à contingência da relação entre $x$ e $y$, equivalendo ao pressuposto 3 elencado por Pearl (2000). Depois de definir o conceito e os critérios de identificação de uma relação causal, o próximo passo é identificar os tipos de causalidade. A figura abaixo ilustra essas informações. 
Figura 2 - Tipos de causalidade

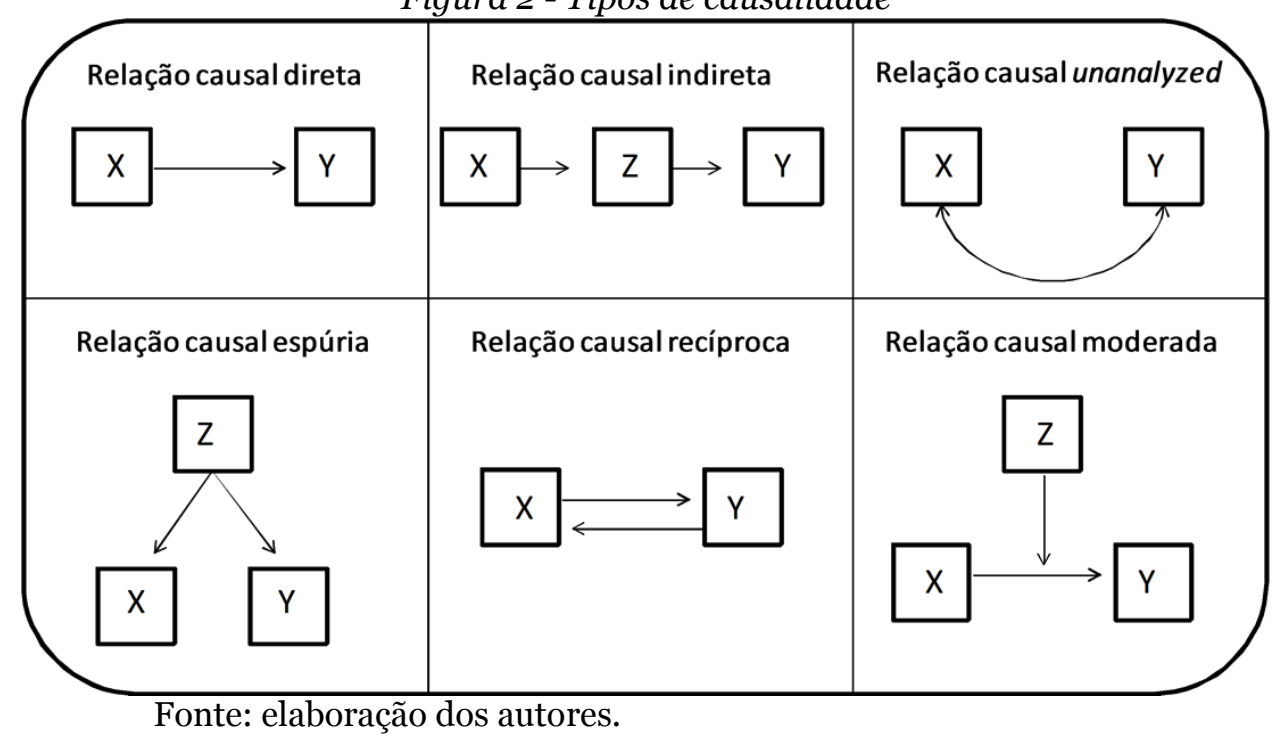

Em geral, hipóteses são formuladas no sentido de identificar relações causais diretas. O objetivo é estimar em que medida uma variável independente $(x)$ pode ser utilizada para explicar a variação de $y$ (variável dependente). No caso da causalidade indireta, o pesquisador deve examinar se $x$ pode ser considerada uma causa independente de $y$, ou se não está condicionada a uma terceira variável, $z$. Imagine a relação entre câncer $(y)$, venda de cigarros $(z)$ e gasto com propaganda tabagista $(x)$. Espera-se que quanto mais cigarros vendidos, maior seja a incidência do câncer. No entanto, não é possível estabelecer diretamente uma relação entre gasto com propaganda e incidência do câncer, a cadeia causal apenas pode ser reconstruída com a inclusão da venda de cigarros $(z)$. Logo, $z$ exerce um efeito direito sobre $y$ enquanto $x$ exerce um efeito indireto.

Na causalidade moderada, há o chamado efeito interativo, isto é, $z$ exerce um impacto sobre o efeito de $x$ sobre $y$. Dito de outra forma, o efeito de $x$ sobre $y$ depende do nível de $z^{13}$. Por exemplo, suponha que o pesquisador está interessado em investigar o efeito da escolaridade $(x)$ sobre a renda $(y)$. Ao comparar homens e mulheres, o

\footnotetext{
${ }^{13}$ Considere o seguinte modelo,
}

$Y=\alpha+\beta_{1} X_{1}+\beta_{2} X_{2}+\varepsilon$

O pressuposto da aditividade assume que o efeito de $X_{1}$ sobre $Y,\left(\beta_{1}\right)$, independe do valor de $X_{2}$. No entanto, dada a complexidade dos fenômenos sociais, é razoável assumir não aditividade ou interação entre as variáveis. No modelo com interação, $Y=\alpha+\beta_{1} X_{1}+\beta_{2} X_{2}+\beta_{3} X_{1} X_{2}+\varepsilon$

o termo interativo $\left(\mathrm{X}_{1} \mathrm{X}_{2}\right)$ captura o efeito condicional das variáveis independentes. Nesse modelo, $\beta_{1}$ representa o efeito de $X_{1}$ sobre $Y$ quando $X_{2}=0$. Similarmente, $\beta_{2}$ representa o efeito de $X_{2}$ sobre $Y$ quando $X_{1}=0$. Para um trabalho clássico sobre termos interativos ver Friedrich (1982). Para uma aplicação bastante didática ver Jaccardi, Turrisi e Wan (1990) e Brambor, Clark e Golder (2006). 
pressuposto é que o efeito da escolaridade é constante para ambos os grupos. No entanto, o pesquisador, teoricamente orientado, sabe que existe preconceito de gênero e que as mulheres mesmo com mais escolaridade auferem renda menor. Para captar esse fenômeno, ele deve inserir um termo interativo entre as variáveis independentes (escolaridade e sexo) na equação de regressão.

Existem ainda as relações causais espúrias e relações causais recíprocas. Nas espúrias, por terem a mesma causa $(z), x$ e $y$ serão correlacionados, mas como $o$ pesquisador não controlou por $z$, ele chega à conclusão equivocada de que $x$ é causa de $y$. Considere a relação entre golfar $(x)$ e engordar $(y)$. Isso porque existe a crença de que bebê que golfa muito, ganha peso mais rápido. No entanto, a correlação observada entre golfar $(x)$ e engordar $(y)$ pode ser explicada na medida em que elas têm a mesma causa: gulodice $(z)$. Ao se controlar pelo efeito da gulodice, a correlação entre as variáveis desaparece, ou seja, a relação era espúria ${ }^{14}$.

Na causalidade recíproca, $x$ influencia $y$, mas $y$ também influencia $x$, não sendo possível estimar com precisão o efeito de uma variável sobre a outra. A modelagem estatística desenvolveu algumas técnicas para lidar com os problemas de endogeneidade. As mais usualmente empregadas são a utilização de variáveis instrumentais e a aplicação de modelos de equações estruturais ${ }^{15}$.

Uma das ferramentas para estabelecer relações causais utilizando dados observacionais são os modelos de regressão ${ }^{16}$. Esses modelos permitem estimar o grau de associação entre $y$, variável dependente e $x_{i}$, conjunto de variáveis independentes. $\mathrm{O}$ objetivo é resumir a correlação entre $x_{i}$ e $y$ em termos da direção (positiva ou negativa) e magnitude. Mais especificamente, é possível utilizar as variáveis independentes para predizer os valores da variável dependente e identificar a contribuição de cada variável

\footnotetext{
${ }_{14}$ Esse exemplo tem sido tradicionalmente utilizado pelo professor Jorge Alexandre no curso intensivo de Metodologia Quantitativa (MQ) em Ciências Sociais da UFMG. De acordo com o Houaiss, o termo gulodice é proveniente da alteração da palavra gulosice e remonta ao século $\mathrm{XV}$. No nordeste brasileiro a palavra gulodice é usualmente utilizada para designar pessoas que comem de forma excessiva.

${ }^{15}$ Enquanto a utilização de variáveis instrumentais tem sido bastante empregada na Economia, os modelos de equações estruturais foram bastante utilizados na Sociologia nas décadas de 1970 e 1980. Para uma introdução as variáveis instrumentais em Ciência Política ver Sovey e Green (2009). Sobre equações estruturais ver Kline (1998) e Bollen (1989, 1993, 2006).

${ }^{16}$ A maior parte dos estudos empíricos em Ciências Sociais realiza inferências utilizando dados observacionais. Recentemente, a utilização de experimentos e quasi-experimentos vem se difundido na Ciência Política. Para os leitores interessados ver Campbell e Stanley (1966), Dean e Voss (1999), Montgomery (2001), Shadish, Cook e Campbell (2002) e Horiuchi, Kosuke e Naoko (2007).
} 
independente sobre a capacidade preditiva do modelo como um todo ${ }^{17}$. Todavia, não existe nenhuma técnica estatística capaz de detectar, sozinha, causalidade entre variáveis. É nesse sentido que a preocupação com a causalidade deve ser um componente central dos desenhos de pesquisa.

King, Keohane e Verba (1994) afirmam que

a major purpose of this book is to show that the differences between the quantitative and qualitative traditions are only stylistic and are methodologically and substantively unimportant. All good research can be understood to derive from the same underlying logic of inference. Both quantitative and qualitative research can be systematic and scientific (KING, KEOHANE e VERBA, 1994, p. 4-5).

Após dez anos da publicação de DSI, Brady e Collier (2004), em Rethinking Social Inquiry, afirmam que "DSI goes too far in advocating the perspective of mainstream quantitative methods as a foundation for research design and qualitative inquiry. We are convinced that this perspective provides an excessively narrow understanding of the research process" (BRADY, COLLIER e SEAWRIGHT, 2004, p. 6/7).

Dentro desse espírito, defendemos que dos dez procedimentos elencados nesse trabalho, apenas o 6 - Produzir inferências causais falsificáveis - não é necessariamente aplicável a desenhos de pesquisa qualitativos. Muitas vezes esses trabalhos não procuram estabelecer relações causais, mas sim compreender e/ou descrever fenômenos. Os demais procedimentos são igualmente aplicáveis a desenhos de pesquisa quantitativos e qualitativos não só em Ciência Política, mas em qualquer área do conhecimento científico. O quadro abaixo ilustra essa ponderação.

Quadro 4-Procedimento por tipo de desenho de pesquisa

\begin{tabular}{|ll|c|c|}
\hline \multicolumn{2}{|c|}{ Procedimento } & Quantitativo & Qualitativo \\
\hline 1. $\quad$ Explicitar a questão de pesquisa & $\mathrm{X}$ & $\mathrm{X}$ \\
\hline 2. $\quad$ Descrever os métodos e as técnicas & $\mathrm{X}$ & $\mathrm{X}$ \\
\hline 3. $\quad$ Simplificar a hipótese de trabalho & $\mathrm{X}$ & $\mathrm{X}$ \\
\hline 4. $\quad$ Produzir inferências causais falsificáveis & $\mathrm{X}$ & $\mathrm{X}$ \\
\hline 5. & Apresentar as limitações do desenho de \\
pesquisa & $\mathrm{X}$ & $\mathrm{X}$ \\
\hline 6. $\quad$ Minimizar a complexidade da linguagem & $\mathrm{X}$ & - \\
\hline 7. & Compartilhar a base de dados & $\mathrm{X}$ & $\mathrm{X}$ \\
\hline
\end{tabular}

${ }_{17}$ Para uma introdução intuitiva ao modelo de regressão de mínimos quadrados ordinários ver Figueiredo Filho et al (2011). 


\begin{tabular}{|l|c|c|}
\hline 8. $\begin{array}{l}\text { Evitar gráficos nebulosos e tabelas poluídas e } \\
\text { incompletas }\end{array}$ & $\mathrm{X}$ & $\mathrm{X}$ \\
\hline 9. Ser criticado antes de publicar & $\mathrm{X}$ & $\mathrm{X}$ \\
\hline $\begin{array}{l}\text { 10. Escolher adequadamente os meios de } \\
\text { divulgação }\end{array}$ & $\mathrm{X}$ & $\mathrm{X}$ \\
\hline
\end{tabular}

Fonte: elaboração dos autores.

A explicitação da questão de pesquisa é um procedimento claramente desejável para qualquer área, na medida em que facilita a compreensão dos propósitos do trabalho. Se não é possível identificar objetivamente a questão de pesquisa, deve ser igualmente complicado avaliar a metodologia, resultados e conclusões. Por sua vez, a simplicidade da linguagem (procedimento 6) é desejável na medida em que constitui o elo da comunicação entre emissor e receptor. Quanto mais confusa a linguagem, maior é a chance de incompreensão da mensagem que o emissor deseja comunicar. $O$ compartilhamento de bases de dados é uma condição essencial para garantir a replicabilidade dos trabalhos. Trabalhos empíricos que não disponibilizam seus dados publicamente são mais difíceis de serem contraditos, pois reduzem a chance de outros pesquisadores colocarem suas conclusões em cheque. A incerteza é um componente essencial do conhecimento científico e quanto mais evidência for produzida em favor de um determinado argumento, menor é a incerteza associada a ele. Todavia, para que os pesquisadores possam sempre duvidar de seus achados, é necessário estabelecer padrões rigorosos de compartilhamento de dados. A não observação desse procedimento favorece que "evidências" sejam criadas por argumentos de autoridade e/ou até mesmo prestígio acumulado em uma determinada área do conhecimento.

Nossa quarta recomendação é que o desenho de pesquisa deve ser formatado no sentido produzir inferências causais falsificáveis.

\section{APRESENTAR AS LIMITAÇÕES DO DESENHO DE PESQUISA}

A ciência é uma atividade, ao mesmo tempo, cooperativa e competitiva. Cooperativa na medida em que o trabalho de um determinado pesquisador se beneficia direta e/ou indiretamente de trabalhos previamente realizados. A cooperação entre pesquisadores e instituições facilita que novos trabalhos sejam realizados, possibilitando aprendizado institucional e humano. Competitiva na medida em que pesquisadores competem por recursos, publicações, espaço em congressos, reconhecimento em suas respectivas áreas de interesse, etc. No entanto, para que a cooperação e a competição influenciem positivamente a qualidade da produção 
científica, é imprescindível que o pesquisador sempre apresente as limitações do seu desenho de pesquisa. As limitações devem ser listadas de forma explícita e pormenorizadas para que a comunidade acadêmica possa avaliar a confiabilidade dos resultados apresentados. Por exemplo, um pesquisador analisa o efeito de x sobre y. Todavia, o número de casos ausentes ultrapassa 50\% das observações. Ele não pode omitir essa informação e deve ponderar como esse problema limita a consistência dos resultados. Um pesquisador interessado em compreender a percepção de mulheres que sofreram agressão sexual deve reportar o percentual de pessoas que se recusaram a responder. Um pesquisador que utiliza a forma funcional de mínimos quadrados ordinários para modelar a variável dependente limitada (zero a 10) deve optar por outros modelos (Tobit, por exemplo) e comparar a consistência das estimativas. Um pesquisador que utiliza dados agregados para realizar inferências para o nível individual deve deixar claro as limitações das inferências produzidas (falácia ecológica). Um pesquisador que utiliza um questionário para mensurar ideologia deve reportar os problemas de mensuração, campo e anexar o instrumento ao paper final. Nas palavras de King (2006),

do not try to hide weaknesses in your paper. If you know of a problem with your analysis that you have not solved, clearly delineate the problem. If you think the problem is not that bad, explain why, but do so honestly. If you have an idea of how to solve it, but haven't done so, offer it as a suggestion for future researchers. If you don't know how to solve it, suggest that future researchers try to tackle it (KING, 2006, p. 122).

A ocultação sistemática das limitações do desenho de pesquisa compromete o desenvolvimento do conhecimento científico. Acreditamos que a incorporação de padrões na formatação dos artigos em Ciência Política é um procedimento desejável e facilitaria a apresentação das limitações enfrentadas pelos pesquisadores. Nas Ciências da Saúde, por exemplo, o padrão IMRAD (introduction, methods, results and discussion) foi institucionalizado desde 1940, chegando a 80\% dos artigos em 1970 e, em 1980, era o único padrão observado em artigos originais (SOLLACI e PEREIRA, 2004) ${ }^{18}$. Esse padrão já foi adotado por alguns periódicos internacionais (por exemplo, American Political Science Review) e facilita a compreensão e avaliação crítica dos resultados. Em particular, a relevância de apresentar as limitações do desenho de pesquisa é ainda maior durante congressos e workshops acadêmicos. Nesses eventos, quanto mais transparência, maior é a chance do pesquisador melhorar o seu desenho de pesquisa e, consequentemente, ofertar um produto de maior qualidade à comunidade científica. Infelizmente, no Brasil, a crítica acadêmica ainda é confundida

${ }_{18}$ Sollaci e Pereira (2004) analisaram quarto diferentes periódicos (British Medical Journal, JAMA, The Lancet e The New England Journal of Medicine) no período entre 1935 e 1985. 
com ataques pessoais. Criticar o trabalho de um colega em um congresso é sinônimo de censura subjetiva. Temos que abandonar esse modelo e aderir ao profissionalismo científico em que a crítica sistemática e construtiva é a alma do negócio.

\title{
6. MINIMIZAR A COMPLEXIDADE DA LINGUAGEM
}

Atribui-se a Rui Barbosa a seguinte passagem:

“Ó, nobre etíope de estatura avantajada! Quanto queres de remuneração pecuniária para trasladar meu indelével corpo deste pólo a aquele hemisfério? Peço-te que uses de magnanimidade ao fazer o cômputo da remuneração monetária a que tens direito, porque apesar da sisudez de minha indumentária estou longe de ser um nababo ou potentado, e não disponho de lastro fiduciário para fazer frente a um débito de maiores proporções"19

O referido jurista queria saber o preço do serviço do transporte. Não se deve confundir profundidade analítica com complexidade linguística. Artigos em Ciência Política devem se afastar do ideal Hegeliano. No prefácio à Fenomenologia do Espírito, o filósofo assim se pronuncia:

\begin{abstract}
O botão desaparece no desabrochar da flor, e poderia dizer-se que a flor o refuta; do mesmo modo que o fruto faz a flor parecer um falso ser-aí da planta, pondo-se como sua verdade em lugar da flor: essas formas não só se distinguem, mas também se repelem como incompatíveis entre si. Porém, ao mesmo tempo, sua natureza fluida faz delas momentos da unidade orgânica, na qual, longe de se contradizerem, todos são igualmente necessários. E essa igual necessidade que constitui unicamente a vida do todo. Mas a contradição de um sistema filosófico não costuma conceber-se desse modo; além disso, a consciência que apreende essa contradição não sabe geralmente libertá-la - ou mantê-la livre - de sua unilateralidade; nem sabe reconhecer no que aparece sob a forma de luta e contradição contra si mesmo, momentos mutuamente necessários (HEGEL, 1988, p. 22).
\end{abstract}

Para McCloskey (1999), não escreva para ser compreendido, mas para evitar a incompreensão. Similarmente, Jim Alt afirma que o pesquisador deve escrever de forma clara e com convicção. A complexidade da linguagem dificulta a vida do leitor, limitando a sua capacidade de avaliar as conclusões de um determinado trabalho. Sugerimos seguir o conselho de Paul Zak: a linguagem deve ser tão simples de modo que a mãe do pesquisador possa compreender. Para King, Keohane e Verba (1994), "the vaguer our language, the less chance we will be wrong but the less chance our work

19 Ver http://www.pluralpluriel.org/index.php?option=com_content\&view=article\&id=311\&Itemid=8 
will be at all useful. It is better to be wrong than vague" (KING, KEOHANE e VERBA, 1994, p. 112). A utilização de metáforas e analogias aumentam a ambiguidade do texto e por isso devem ser evitadas.

Termos como "não se pode olvidar", "hodiernamente", "ilações", "cratológico", "abalizar", entre outros, também devem ser evitados ${ }^{20}$. Qual é o sentido de publicar um artigo com uma linguagem tão burilada que apenas egrégias mentes são capazes de proceder a sua exegese? Exatamente, nenhum.

Cada área do conhecimento tem um vocabulário específico. É importante que o pesquisador se familiarize e utilize os termos comumente empregados em sua área de interesse. Por exemplo, não escreva construção institucional, empregue desenho institucional. Não use introito, prefira introdução.

$\mathrm{Na}$ ausência de traduções amplamente compartilhadas, o pesquisador deve preservar o vocábulo original. Não escreva accountabilidade, mantenha o termo accountability. Além disso, deve-se ter cuidado com os falsos cognatos. Não traduza policies como apólice. Na dúvida, deve-se procurar ajuda de outros pesquisadores. Adjetivos também devem ser evitados. Não escreva o "inesquecível Barry Ames”, nem o “imbatível Scott Mainwaring”. Artigos em Ciência Política se limitam a informar autor (ano). Tecnicamente, frases entre vírgulas e sujeitos ocultos, além da utilização de mesóclises produzem ambiguidade, devendo ser evitadas. Por exemplo, é preferível escrever "esse trabalho estima o efeito da agenda política dos governadores sobre o comportamento dos deputados em plenário" do que afirmar que "nesse trabalho, estimar-se-á, como e em que medida, o comportamento dos deputados em plenário é influenciado pela agenda política dos governadores".

Evite também a utilização da voz passiva. Por exemplo, não escreva que "nesse trabalho foi utilizada a metodologia de estudo de caso para analisar como a estabilidade econômica é influenciada pelo regime político", opte por "esse trabalho utiliza a metodologia de estudo de caso para analisar como o regime político influencia a estabilidade econômica”. Portanto, nossa sexta recomendação é minimizar a complexidade da linguagem.

\section{COMPARTILHAR AS BASES DE DADOS}

De acordo com Gleditsch, Metelits e Strand (2003), autores que disponibilizam seus dados são duas vezes mais citados do que aqueles que não o fazem. Tem-se aqui o

${ }^{20}$ Esse ponto foi enfatizado pelo professor Marcus Melo (UFPE) durante a disciplina Tópicos Especiais de Ciência Política. 
primeiro incentivo para compartilhar bases de dados. Uma segunda vantagem do compartilhamento de bases de dados é a replicabilidade (replication), ou seja, o processo pelo qual novas análises podem ser realizadas a partir de um banco de dados já existente com o objetivo de aprimorar os resultados de pesquisa. A replicação permite que outros pesquisadores melhorem nossas análises, demonstrando inclusive que nossos resultados estavam errados. Por exemplo, Dewald, Thursby e Anderson (1986) replicaram os resultados de diferentes artigos e constataram que erros sistemáticos são frequentes. Resultados de pesquisa de especialistas que compartilham bases de dados são mais facilmente replicáveis e, portanto, mais facilmente falsificáveis.

Para o pesquisador comprometido com o desenvolvimento do conhecimento científico, quanto mais falsificáveis forem seus resultados, tanto melhor. Quão frutífero seria para o desenvolvimento da Ciência Política brasileira se ao acessar um artigo qualquer do Scielo, o estudante/pesquisador pudesse ter acesso aos dados utilizados? Em 2009, a Corte de Apelação (Court of Appeals) norte-americana confirmou a decisão do Corte Distrital, indeferindo um pedido de ação de difamação de Lott contra Levitt. O nome de Lott foi citado no livro Freaknomics como exemplo de trabalho não replicável. Lott argumentou que no contexto citado ele estaria sendo acusado de desonestidade

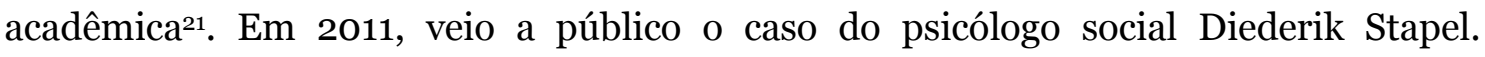
Considerado um dos mais prestigiados pesquisadores da Holanda, tendo publicado artigo na revista Science. De acordo com as investigações, Stapel inventava a maior parte dos seus dados. Curiosamente, seus estudantes de doutorado reportaram que Stapel nunca os permitia participar da coleta dos dados ${ }^{22}$. A replicabilidade protege a comunidade científica não só de fraudes deliberadas, mas também de erros honestos e das limitações técnicas dos pesquisadores.

King (1995) afirma que algumas medidas podem incentivar o padrão de replicabilidade. A primeira delas é incluir a disponibilização de banco de dados como um indicador de produtividade acadêmica como a publicação de um artigo ou livro. Outra medida é exigir que alunos de mestrado e doutorado disponibilizem os bancos de dados utilizados em suas pesquisas. O terceiro envolve a política de publicação dos periódicos especializados. Alguns periódicos em Ciência Política já exigem a disponibilização do banco de dados em algum repositório de acesso público como

${ }^{21}$ Ver http://caselaw.Öndlaw.com/us-7th-circuit/1139405.html ${ }^{22}$ Verhttp://veja.abril.com.br/noticia/brasil/holandeses-se-surpreendem-com-fraude-deprestigiado-psicologo 
condição para publicação do artigo. Destacamos a iniciativa da Revista Leviathan que além de exigir o banco de dados como critério de publicação, aceita artigos em formato .tex No plano internacional tem-se o Inter University Consortium for Political and Social Research (ICPRS) da Universidade de Michigan. No Brasil, o Consórcio de Informações Sociais (CIS) conta com um acervo significativo de bases de dados que podem ser publicamente acessadas, mediante cadastro no sistema. Comparativamente, o Dataverse Network, organizado pelo The Institute for Quantitative Social Science da Universidade de Harvard, disponibiliza o maior repositório de dados em Ciências Sociais do mundo. O sistema é público e bastante amigável.

Pedagogicamente, o padrão de replicabilidade facilita que estudantes dêem seus primeiros passos no mundo da pesquisa empírica. Para King (1995), "having students replicate the results of existing articles has proven to be an effective teaching tool" (KING, 1995, p. 447). Por exemplo, aprender que a correlação de Pearson mede o grau de associação entre peso e altura é importante. No entanto, a aprendizagem é mais eficiente quando os estudantes podem estimar o grau de associação entre variáveis utilizadas em desenhos de pesquisa em Ciência Política. Na Universidade Federal de Pernambuco (UFPE), o professor Enivaldo Rocha incorporou o padrão de replicabilidade como um dos componentes da disciplina Tópicos Avançados de Metodologia de Pesquisa ${ }^{23}$.

No entanto, apesar dessas iniciativas, não existe uma política sistemática de incentivos ao compartilhamento de dados por parte da comunidade acadêmica. King (1995) questiona a importância das inferências produzidas por um desenho de pesquisa não replicável, afirmando que "at a minimum, some protection should be afforded to keep researchers from wasting their time reading these works" (KING 1995, p. 445). Concordamos com o professor King e elencamos o compartilhamento de bases de dados como a sétima recomendação para agregar qualidade aos desenhos de pesquisa em Ciência Política.

\section{EVITAR GRÁFICOS NEBULOSOS E TABELAS INCOMPLETAS E POLUÍDAS ${ }^{24}$}

\footnotetext{
${ }^{23}$ Um dos resultados dessa opção pedagógica foi a publicação de três artigos sobre métodos e técnicas. O primeiro - O que fazer e o que não fazer com a regressão: pressupostos e aplicações do modelo linear de mínimos quadrados ordinários, publicado pela revista Política Hoje. $\mathrm{O}$ segundo foi What is R2 all about? publicado pela revista Leviathan e o terceiro foi Classificando regimes políticos utilizando análise de conglomerados, veiculado pela revista Opinião Pública. 24 Sobre as vantagens analíticas de gráficos ao invés de tabelas ver Kastellec e Leoni (2007). Tufte (1983) apresenta o trabalho seminal sobre a visualização gráfica de resultados de pesquisa. Ver http://www.edwardtufte.com/tufte/books vdqi.
} 
A representação gráfica é um elemento decisivo para facilitar a compreensão dos resultados de pesquisa. Kastellec e Leoni (2007) argumentam que a análise gráfica é mais intuitiva do que o padrão convencional utilizando tabelas. No entanto, para que a máxima de que uma imagem vale mais do que mil palavras seja verdadeira, é necessário que o pesquisador apresente seus resultados de forma adequada. Gráficos nebulosos depõem não só contra a credibilidade dos resultados de pesquisa, mas também contra a capacidade técnica do pesquisador na execução do seu trabalho.

Quatro procedimentos são centrais para evitar gráficos nebulosos. O primeiro é a descrição dos rótulos das variáveis (labels). Sem essa informação o leitor nunca saberá que variável está em cada eixo. O segundo é assegurar que o tamanho da fonte utilizada seja facilmente legível. Nenhum ganho analítico pode ser produzido por um gráfico que força a visão do leitor. De forma complementar, o pesquisador deve evitar a utilização de fontes pouco convencionais, tomando como exemplo os periódicos mais prestigiados (Political Analysis, American Political Science Review, American Journal of Political Science, etc.). O terceiro procedimento é maximizar a quantidade de informação por $\mathrm{cm}^{2}$ sem comprometer a inteligibilidade dos resultados. Estilisticamente, para assegurar gráficos ainda mais profissionais, o pesquisador deve limitar a quantidade de cores, estabelecendo um padrão. Por fim, um procedimento para evitar gráficos nebulosos é garantir a compatibilidade entre o nível de mensuração das variáveis e o tipo de gráfico utilizado. Por exemplo, gráficos de pizza não devem ser utilizados para ilustrar médias. Ou, variáveis categóricas não devem ser utilizadas nos eixos de gráficos de dispersão.

A representação gráfica de dados facilita a comunicação entre o emissor da informação e o receptor. Para otimizar esse processo, o pesquisador deve adequar o tipo de gráfico utilizado ao nível de mensuração das variáveis. Considere a figura abaixo. 
Figura 4 - Transformando um gráfico nebuloso
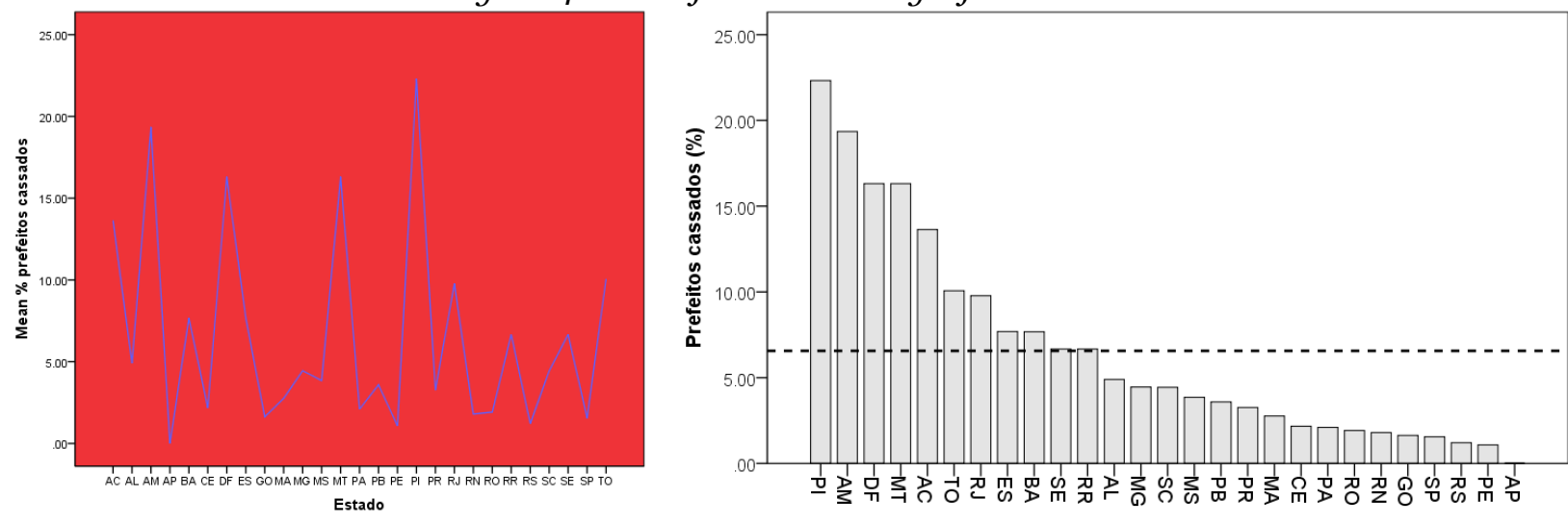

Fonte: elaboração dos autores.

O objetivo é mostrar como o percentual de cassação de prefeitos varia por estado. O gráfico de linha é mais indicado quando a variável tempo é incluída no eixo $x$. Além disso, o fundo vermelho com a tonalidade azul da linha é visualmente desagradável. O rótulo da variável estado é desnecessário já que a própria categoria informa o que está sendo analisado. Por sua vez, o rótulo da variável dependente, no entanto, apresenta uma fonte inadequada, dificultando a compreensão do gráfico. A conversão do gráfico nebuloso em um não nebuloso é simples. O primeiro passo é identificar um tipo mais adequado. Como o objetivo é a comparação entre estados, é desejável que o pesquisador ordene as unidades da federação a partir da distribuição da variável dependente para facilitar a compreensão dos resultados. A inclusão de um parâmetro de referência também produz ganhos analíticos, nesse caso, incluímos a linha pontilhada simbolizando a média do percentual de cassação dos prefeitos.

Desafio para o leitor: identifique no gráfico nebuloso quais são os estados com o maior e o menor percentual de prefeitos cassados. Essa mesma informação pode ser rapidamente coletada ao analisar o gráfico não nebuloso. Tão importante quanto evitar gráficos nebulosos é evitar tabelas poluídas e incompletas. O pesquisador comprometido com o avanço do conhecimento científico deve zelar pela qualidade da representação tabular dos seus resultados de pesquisa. A figura abaixo ilustra sete problemas que devem ser superados. 
Tabela 1 - Sete pecados

\begin{tabular}{|c|c|}
\hline Pais & PIB \\
\hline$X$ & $\mathrm{R} \$ 2.000,1357$ \\
\hline $\mathrm{Y}$ & $\mathrm{R} \$ 12.000,2468$ \\
\hline $\mathrm{Z}$ & $\mathrm{R} \$ 24.000 .1234$ \\
\hline
\end{tabular}

Tabela XX - PIB e PIB per capita por país (R\$)

\begin{tabular}{c|c|c}
\hline \hline País & PIB & PIB per capita \\
\hline $\mathbf{X}$ & $2.000,14$ & 200,00 \\
\hline $\mathbf{Y}$ & $12.000,25$ & 100,00 \\
\hline $\mathbf{Z}$ & $24.000,12$ & 80,00
\end{tabular}

Fonte: elaboração própria a partir do IBGE (2000)

A tabela da esquerda apresenta uma série de problemas. O primeiro é que ela não é uma tabela, mas sim um quadro. Tabelas devem ser vazadas na lateral. $\mathrm{O}$ segundo problema é a ausência de título e fonte. O terceiro inconveniente é a combinação das cores. Além de visualmente desagradável, a linha branca associada ao país Y chama a atenção do leitor de forma equivocada. As ênfases gráficas devem ter uma função analítica e não meramente estilística. De acordo com King (1995), tabelas devem elaboradas somente em tons de preto e branco. O quarto problema refere-se à falta de acentuação da palavra país, o que sugere falta de cuidado do pesquisador na formatação do trabalho. O excesso de erros formais compromete a credibilidade dos achados de pesquisa. Por que o leitor deve confiar nos resultados quando diferentes erros são encontrados ao longo do texto? O quinto problema é a repetição desnecessária da expressão $\mathrm{R} \$$. Qual o ganho analítico em repeti-lo três vezes? Nenhum. O sexto problema é a utilização de diferentes sistemas decimais. Observe que a linha associada ao país $\mathrm{Z}$ utiliza ponto (.), enquanto as demais linhas utilizam vírgulas (,). Além disso, há um excesso de algarismos depois das casas decimais que não fornece nenhum ganho substantivo de informação, pelo contrário, polui a tabela. Por fim, o sétimo problema é a utilização de uma medida absoluta quando o objetivo do pesquisador é realizar uma comparação. Essa deficiência é recorrente e desastrosa já que comparações realizadas a partir de dados absolutos são desprovidas de sentido. $\mathrm{O}$ pesquisador também deve evitar exportar diretamente as tabelas produzidas pelos programas de análise de dados para o seu artigo/desenho de pesquisa. A superação desses obstáculos confere maior rigor formal ao desenho de pesquisa.

Nossa oitava recomendação para elevar a qualidade de artigos/desenhos de pesquisa é evitar gráficos nebulosos e tabelas poluídas e incompletas. 


\section{SER CRITICADO ANTES DE PUBLICAR}

O pesquisador que submete diretamente seu trabalho às revistas especializadas assume dois pressupostos: (1) o corpo editorial do periódico escolhido reúne os pareceristas mais aptos a oferecer a melhor contribuição possível ao aprimoramento de sua pesquisa e (2) o trabalho foi de fato alocado para o parecerista mais apto a oferecer a melhor contribuição possível. A pergunta é: qual é a probabilidade de satisfazer esses pressupostos? Quando um working paper é apreciado pela comunidade acadêmica, o pesquisador recebe diferentes sugestões sobre como melhorar a qualidade do seu desenho de pesquisa. Existe uma série de benefícios associados a esse procedimento: (1) erros de formatação do trabalho podem ser mais facilmente detectados; (2) problemas relacionados à mensuração das variáveis podem ser superados; (3) bibliografia até então desconhecida passa a ser parte integrante do quadro teórico; (4) bancos de dados outrora desconhecidos podem ser utilizados para suprir a necessidade por mais informações; (5) periódicos até então ignorados passam a ser potenciais alternativas de publicação; (6) o pesquisador descobre que existem outros desenhos de pesquisa similares com conclusões parecidas ou antagônicas.

Em síntese, o crivo da comunidade acadêmica é uma das formas mais eficientes de aprimorar desenhos de pesquisa e, posteriormente, resultados de pesquisa. Apenas depois de submeter seu trabalho às críticas, o pesquisador deve submetê-lo aos periódicos especializados. O ganho é evidente: aumenta-se não só a probabilidade de ter um trabalho aceito, mas também, e mais importante, a chance do trabalho contribuir com o desenvolvimento do conhecimento em uma determinada área. A ciência se beneficia muito mais quando um pesquisador consegue aprimorar seu artigo/desenho de pesquisa mediante crítica do que com a publicação de um trabalho recém terminado e não criticado pela comunidade acadêmica.

\section{ESCOLHER ADEQUADAMENTE OS MEIOS DE DIVULGAÇÃO}

Tão importante quanto formular e executar um desenho de pesquisa é escolher os meios apropriados para divulgar o resultado/produto final do trabalho. Recomendamos que estudantes e pesquisadores se informem a respeito da política editorial das revistas. Por exemplo, se o artigo é empírico, deve-se evitar submetê-lo a um periódico de orientação majoritariamente teórica. Similarmente, se o artigo partilha de uma epistemologia positivista, também é indicado que o pesquisador evite submetêlo a revistas de orientação construtivista. Outro elemento importante é examinar em que medida o tema do artigo do pesquisador já foi contemplado por outros trabalhos 
publicados na revista. Uma estratégia eficaz é replicar os resultados de um determinado artigo e submeter o novo trabalho ao mesmo periódico que publicou o artigo original (KING, 1995).

Quem já submeteu um artigo a um periódico sabe que o tempo de espera é longo. Nosso conselho para minimizar o tempo entre a submissão e a resposta é seguir, rigorosamente, as regras específicas de cada revista. O pesquisador deve obedecer os procedimentos formais de citação e de referências bibliográficas. Outro elemento essencial é tentar incorporar ao máximo a quantidade de recomendações dos pareceristas. Primeiro, a incorporação sistemática das sugestões eleva a probabilidade do artigo ser publicado. Em segundo lugar, ao incorporar as sugestões, o autor agrega diferentes pontos de vistas que, muitas vezes, podem passar despercebidos para o pesquisador. A formatação e a apresentação do artigo também são importantes. Por exemplo, sempre que trabalhar com fórmulas matemáticas ${ }^{25}$, é desejável utilizar softwares específicos para garantir a qualidade da apresentação gráfica.

Por fim, o pesquisador deve considerar a qualidade dos periódicos. Por exemplo, o sistema Qualis Periódicos ${ }^{26}$ da Coordenação de Aperfeiçoamento de Pessoal de Nível Superior (CAPES) hierarquiza os periódicos em diferentes estratos. O pesquisador deve orientar a sua produção a partir de padrões de excelência e focar em periódicos prestigiosos. Pouco avança o conhecimento científico quando um artigo é publicado em uma revista que ninguém lê. O pesquisador não deve ficar desanimado quando receber um parecer negativo. Isso não é uma prova irrefutável de que o artigo não apresenta uma contribuição relevante. Por exemplo, o primeiro livro do Harry Porter, de J.K Rowling, foi rejeitado por nove editores antes de ser publicado. O manuscrito de Tempo de Matar de John Grisham foi rejeitado por 26 editores (MLODINOW, 2009, p. 31).

Em síntese, recomendamos que pesquisadores observem atentamente as políticas editoriais dos periódicos, prezando pela qualidade de apresentação e

25 Sugerimos os seguintes softwares para elaboração de fórmulas matemáticas e edição de documentos:

http://www.latex-project.org/ http://www.mackichan.com/index.html?products/swp.html mainFrame

${ }^{26}$ A estratificação da qualidade dessa produção é realizada de forma indireta. Dessa forma, o Qualis afere a qualidade dos artigos e de outros tipos de produção, a partir da análise da qualidade dos veículos de divulgação, ou seja, periódicos científicos. A classificação de periódicos é realizada pelas áreas de avaliação e passa por processo anual de atualização. Esses veículos são enquadrados em estratos indicativos da qualidade - A1, o mais elevado; A2; B1; B2; B3; B4; B5; C. Para acessar: http://www.capes.gov.br/avaliacao/qualis 
substância de seus artigos e priorizando os periódicos mais influentes em suas respectivas áreas de atuação.

\section{CONSIDERAÇÕES FINAIS}

É exatamente a metodologia de pesquisa que distingue o conhecimento científico de outras formas de conhecimento (senso comum, religioso e filosófico). Esse trabalho apresentou dez condutas que ajudam o pesquisador a melhorar a qualidade do seu desenho e/ou produto final de pesquisa. Nosso público alvo é exatamente estudantes de graduação e pós-graduação e pesquisadores em Ciência Política. Acreditamos que um procedimento essencial para elevar a qualidade do conhecimento científico é garykingzar os desenhos e/ou produtos finais de pesquisa, ou seja, seguir as dez condutas aqui elencadas que são amplamente aceitas pela comunidade científica como boas práticas de pesquisa. Garykingzar no sentido de que questões de pesquisa sejam sempre explícitas e que os trabalhos utilizem sempre uma linguagem simples, direta e objetiva. Que os pesquisadores compartilhem suas bases de dados e descrevam detalhadamente os métodos e técnicas utilizados. Garykingzar no sentido de que as hipóteses de pesquisa sejam parcimoniosas e os trabalhos empíricos busquem estabelecer inferências causais falsificáveis. Que os pesquisadores sempre apresentem as limitações do desenho de pesquisa, bem como, evitem gráficos nebulosos e tabelas poluídas e incompletas. Garykingzar no sentido de que a crítica seja feita de forma profissional no mundo acadêmico e não se torne perseguições pessoais. A propósito, retomando um dos argumentos aqui trabalhados, não só a própria elaboração do desenho de pesquisa, como as considerações finais devem ser concisas e parcimoniosas.

\section{REFERÊNCIAS BIBLIOGRÁFICAS}

AMORIN NETO, O. e SANTOS, F. (2003). O segredo ineficiente revisto: o que propõem e o que aprovam os deputados brasileiros. Dados - Revista de Ciências Sociais, Rio de Janeiro, v.46, n. 4, p. 661-698.

BHASKAR, R. (1997). A realist theory of science. $2^{\circ}$ ed., Londres, Verso.

BLALOCK, H. (1967). Causal Inferences, Closed Populations, and Measures of Association. The American Political Science Review, 61, 1, 130-136.

BOLLEN, K. A. (1989). Structural Equations with Latent Variables. Wiley Series in Probability and Mathematical Statistics. New York: Wiley, 514 pages.

BOLlen, K. A. and CURRAN, P. J. (2006). Latent Curve Models: A Structural 
Equation Perspective. Wiley Series in Probability and Mathematical Statistics. New York: Wiley, 285 pages.

BOLLEN, K. A. and LONG, J. S. (eds) (1993). Testing Structural Equation Models. Newbury Park, CA: Sage, 320 pages.

BRADY, H., and COLLIER, D. (2004). Rethinking social inquiry: Diverse tools, shared standards. Lanham, MD: Rowman \& Littlefield.

BRAMBOR T, CLARK, W., and GOLDER M. (2006). Understanding interaction models: Improving empirical analyses. Political Analysis, 14(1): 63-82.

BUNGE, M. (1997). Mechanism and Explanation. Philosophy of the Social Science, 27, 4, 410-465.

CAMPBELL, D. and STANELY, J. (1966). Experimental and Quasi-Experimental Deseigns for Research. Rand McNally, Chicago, Illinois.

CHALMERS, A. (1993). O que é ciência afinal? Ed. Brasiliense: São Paulo.

CHEN, P. e POPOVIC, P. (2002). Correlation. London, Sage.

DEAN, A. e VOSS, D. (1999). Design and Analysis of Experiments. Springer, New York.

DELLA PORTA, D.; KEATING, M. (eds). (2008). Approaches and Methodologies in the Social Sciences. A Pluralist Perspective, Cambridge: Cambridge University Press.

DEWALD, W. G., J. G. THURSBY, and R. G. Anderson (1986). Replication in empirical economics: The Journal of Money, Credit, and Banking project. The American Economic Review 76:587-603.

ELSTER, J. (1989). Nuts and Bolts for the Social Sciences. Cambridge, Cambridge University Press.

FIGUEIREDO, A. e LIMONGI, F. (1999). Executivo e Legislativo na Nova Ordem Constitucional. Rio de Janeiro: Ed. FGV.

FIGUEIREDO FILHO, D. B., SILVA JÚNIOR, J. A., ROCHA, E. C. (2011). What is R2 all about? Leviathan - Cadernos de Pesquisa Política, v. 3, p. 60-68.

FIGUEIREDO FILHO, D. B., SILVA JÚNIOR, J. A. e ROCHA, E. C. Classificando regimes políticos utilizando análise de conglomerados. Opinião Pública (UNICAMP. Impresso), 2012.

FIGUEIREDO FILHO, D., SILVA JUNIOR, J. e ROCHA, E. (2011). O que fazer e o que não fazer com a regressão: pressupostos e aplicações do modelo linear de Mínimos Quadrados Ordinários (MQO). Revista Política Hoje, v. 20, 1, 44-99.

FRIEDRICH, R. (1982). In Defense of Multiplicative Terms in Multiple Regression Equations. American Journal of Political Science 26(4), 797-833. 
GEDDES, B. (2003). Paradigms and Sand Castles: Theory Building and Research Design in Comparative Politics. Ann Arbor: University of Michigan Press.

GERRING, J. (2005). Causation: A Unified Framework for the Social Sciences. Journal of Theoretical Politics 17, 2, 163-98.

GERRING, J. (2001). Social Science Methodology: A Criterial Framework, Cambridge University Press.

GLEDITSCH, N. P, METELITS, C. and STRAND, H. (2003). Posting Your Data: Will You be Scooped or Will You be Famous? International Studies Perspectives 4: 89-97

HEDSTRÖM, P. and SWEDBERG, R. (1998). "Social Mechanisms: An Introductory Essay”, IN: P. Hedström e R. Swedberg (eds.), Social Mechanisms: An Analytical Approach to Social Theory. New York, Cambridge University Press.

HIRSCHI, T. e SELVIN, H. (1973). "False Criteria of Causality." IN: Principles of Survey Analysis. New York: The Free Press.

HOLLAND, P. (1986). "Statistics and Causal Inference". Journal of the American Statistical Association, 81: 945-60.

HORIUCHI, Y.; IMAI, K and TANGUCHI, N. (2007). Designing and analyzing randomized experiments: application to a Japanese Election Survey Experiment. American Journal of Political Science, Vol. 51, nº 3 (July), pp. 669-687.

JACCARD, J., TURRISI, R., and WAN, C. (1990). Interaction Effects in Multiple Regression. Newbury Park, CA: Sage.

KENNEDY, P. (2009) A Guide to Econometrics. Boston: MIT Press.

KASTELLEC, J. P. e LEONI, E. (2007) Using Graphs Instead of Tables in Political Science. Perspectives in Politics, vol. 5, n. 4.

KENNY, D. Correlation and Causality. (2004). Virginia Carrow. Disponível em: http://www.davidakenny.net/books.htm

KING, G. (2006). Publication, Publication. PS: Political Science and Politics 39: 119125. Disponível: http://gking.harvard.edu/files/paperspub.pdf

KING, G. (2003). The Future of Replication. International Studies Perspectives 4: 443499. Disponível: http://gking.harvard.edu/gking/files/replvdc.pdf

KING, G. (1995). Replication, Replication. PS: Political Science and Politics 28: 443499. Disponível: http://gking.harvard.edu/gking/files/replication.pdf

KING, G., KEOHANE, R. e VERBA, S. (1994). Designing Social Inquiry: Scientific Inference in Qualitative Research. Princeton. N.J.: Princeton University Press.

KITSCHELT, H. (2003). "Accounting for Postcommunist Regime Diversity: What Counts as a Good Cause?" IN: G. Ekiert and S. Hanson, eds., Capitalism and Democracy in Central and Eastern Europe, Cambridge University Press, 49-86.

KLINE, R. B. (1998). Principles and practices of structural equation modeling. New York: Guilford. 
KUNH, T. (1975). A estrutura das revoluções científicas. $3 \cdot^{\text {a }}$ edição. São Paulo: Perspectiva.

LEE, A. (1991). Integrating Positivist and Interpretive Approaches to Organizational Research. Organization Science, 2, 4, 342-365.

LEVITT, S. (2005) Freakonomics - o lado oculto e inesperado de tudo que nos afeta. Rio de Janeiro: Elsevier.

MAHONEY, J. (2001). Path-Dependent Explanations of Regime Change: Central America in Comparative Perspective. Studies in Comparative International Development, 36:1.

MARQUES, E. (2006). Dossiê: Métodos e Explicações da Política. Para onde nos levam os caminhos recentes? Associação Nacional de Pós-Graduação e Pesquisa em Ciências Sociais (ANPOCS), 2006. Revista Brasileira de Ciências Sociais, 2007.

MARSH, D. e FURLONG P. (2002). "A Skin not a Sweater: Ontology and Epistemology in Political Science", in: D. Marsh and G. Stoker (eds.), Theory and Methods in Political Science, Basingstoke: Palgrave, p. 17-44.

McCLOSKEY, D. (1999). Writing of Economics. 2 ed. MacMillan.

MERTON, R. (1968). Social Theory and Social Structure. NewYork, The Free Press.

MONTGOMERY, D. (2001). Design and analysis of experiments ( $5^{\text {th }}$ edn.). New York: John Wiley \& Sons.

PEARL, J. (2000). Causality: Models, reasoning, and inference. New York: Cambridge University Press.

POPPER, Karl (1968). The Logic of Scientific Discovery. Londres: Hutchinson.

RATTON JUNIOR, J. e MORAIS, J. (2003). "Para Ler Jon Elster: Limites e Possibilidades da Explicação por Mecanismos nas Ciências Sociais." DADOS - Revista de Ciências Sociais, Rio de Janeiro, 46, 2, 385-410.

RUBIN, D. (1974). "Estimating Causal Effects of Treatments in Randomized and Nonrandomized Studies.” Journal of Educational Psychology 66 (5): 688-701.

SALMON, W. (1984). "Scientific Explanation: Three Basic Conceptions. Proceedings of the Biennial Meeting of the Philosophy of Science Association." Symposia and Invited Papers, 2, 293-305.

SANDERS, D. (2002). "Behaviouralism”, IN D. Marsh and G. Stoker (eds.), Theory and Methods in Political Science, Basingstoke: Palgrave, p. 45-64.

SCHMITTER, P. (2002). The Ideal Research Proposal. Disponível: http://www.eui.eu/Documents/DepartmentsCentres/SPS/Profiles/Schmitter/IdealRes earchProposal.pdf 
SHADISH, R., COOK, T. e CAMPBELL. (2002). Experimental and quasi-experimental Designs of generalized causal inference. Houghton Mifflin Company Boston New York.

SOARES, G. A. D. (2006). "O calcanhar metodológico da ciência política no Brasil". In: Carlos Benedito Martins (org.). Para onde vai a pós-graduação em ciências sociais no Brasil. São Paulo, CAPES / EDUSC/ ANPOCS, 2005, pp. 73-104.

SOVEY, A. J. and GREEN, D. P. (2009). "Instrumental-Variables Estimation in Political Science: A Readers' Guide.” Paper prepared for the 26th Annual Society for Political Methodology Summer Conference, Yale University, July 23-25.

SPECTOR, P. E. (1981). Research designs. Beverly Hills, CA: Sage Publications.

STACE, W. (1944). Positivism. Mind, New Series, 53, 211: 215-237.

STINCHCOMBE, A. (1968). “The Logic of Scientific Inference.” Ch. 2, pp. 15-37 In Constructing Social Theories. New York: Harcourt, Brace and World.

STINCHCOMBE, A. (1991). The Conditions of Fruitfulness of Theorizing About Mechanisms in Social Science. Philosophy of the Social Sciences, 21, 3, 367-388.

TILLY, C. (2001). Mechanisms in political process. Annual Review of Political Science, 4, 21-41.

TUFTE, E.R. (1983) The Visual Display of Quantitative Information. Graphics Press.

VAN EVERA, S. (1997). Guide to Methods for Students of Political Science. Ithaca, NY: Cornell University Press.

WOOLDRIDGE, J. (2009). Econometrics: a modern approach. $4^{\text {a }}$ Ed. South-Western, Cengage Learning.

ZALD, M. (1995). Progress and Cumulation in the Human Sciences after the Fall. Sociological Forum, 10, 3 pp. 455-479. 